\title{
Composição química e atividade inseticida do óleo essencial de Schinus terebinthifolius Raddi (Anacardiaceae) sobre a broca-do-café (Hypothenemus hampei) Ferrari
}

\author{
SANTOS, M.R.A. ${ }^{1}$; LIMA, R.A. ${ }^{12^{*}}$; SILVA, A.G. ${ }^{1}$; LIMA, D.K.S. ${ }^{1}$; SALLET, L.A.P. ${ }^{1}$; TEIXEIRA, C.A.D. ${ }^{1}$; FACUNDO, \\ V.A. ${ }^{2}$ \\ ${ }^{1}$ Embrapa Rondônia - BR 364, km 5,5, Caixa Postal 127, CEP: 76815-800, Porto Velho-Rondônia, Brasil; \\ *renatoabreu07@hotmail.com ${ }^{2}$ Laboratório de Produtos Naturais da Universidade Federal de Rondônia, BR \\ 364, km 9,5, CEP: 78900-000, Porto Velho-Rondônia, Brasil.
}

\begin{abstract}
RESUMO: O óleo essencial das folhas de Schinus terebinthifolius foi obtido por hidrodestilação e analisado por CG-EM. O rendimento do óleo foi de $0,8 \%$, sendo identificados 37 constituintes químicos. Os componentes principais foram germacreno $D(25,0 \%),(E)$ - $\beta$-cariofileno $(17,5 \%)$ e $\delta$-elemeno $(10,5 \%)$. O óleo essencial foi diluído em acetona nas concentrações de $10^{-2}$ a $10^{-8}$ e aplicado aos insetos (Hypothenemus hampei) por aplicação tópica e exposição em superfície contaminada. As taxas de mortalidade foram avaliadas após 24 e 48 horas do início do experimento. A aplicação em superfície contaminada resultou em $25 \%$ de mortalidade no controle, enquanto nas diluições de $10^{-2}$ a $10^{-8}$ foram observados 100,0 a $30,0 \%$ de mortalidade. $\mathrm{Na}$ aplicação tópica, observou-se $27,5 \%$ de mortalidade no controle e 97,5 a $77,5 \%$ nas diluições de $10^{-2}$ a $10^{-8}$.
\end{abstract}

Palavras-chave: cafeicultura, aroeira vermelha, inseticida natural, metabólitos secundários.

ABSTRACT: Chemical composition and insecticidal activity of the essential oil of Schinus terebinthifolius Raddi (Anacardiaceae) on coffee berry borer (Hypothenemus hampei) Ferrari. The essential oil from the leaves of Schinus terebinthifolius was obtained by hydrodistillation and was analyzed by GC-MS. The oil yield was $0.8 \%$, and 37 chemical constituents were identified. The main components were germacrene $D(25.0 \%),(E)-\beta-$ cariophyllene $(17.5 \%)$ and $\delta$-elemene $(10.5 \%)$. The essential oil was diluted in acetone in concentrations of $10^{-2}$ to $10^{-8}$ and it was applied to insects (Hypothenemus hampei) by topical application and exposure to contaminated surface. Mortality rates were evaluated after 24 and 48 hours. The contaminated surface application resulted in $25.0 \%$ of mortality in control while the dilutions of $10^{-2}$ to $10^{-8}$ resulted in $100 \%$ to $30.0 \%$ of mortality respectively. In the topical application, it was observed $27.5 \%$ of mortality in control and 97.5 to $77.5 \%$ of mortality in dilutions of $10^{-2}$ to $10^{-8}$.

Keywords: coffee, red aroeira, natural insecticide, secondary metabolites.

\section{INTRODUÇÃO}

A cafeicultura é responsável por grande movimentação de recursos financeiros no Brasil, abrangendo desde a contratação de mão-de-obra para a realização de tratos culturais, a negociação de grandes lotes de insumos e máquinas, até a comercialização do produto final (GUIMARÃES, 2002).

Atualmente, o café é um importante produto do agronegócio brasileiro, tendo um valor histórico e principalmente econômico para o Brasil, destacando-se como o principal produtor mundial (CONAB, 2011). A produção cafeeira do Brasil está distribuída principalmente nos Estados de Minas Gerais, Espírito Santo, São Paulo, Paraná, Rondônia e Bahia (CONAB, 2011). Em Rondônia, seu plantio ocorre desde a década de 1970, constituindo-se na base econômica de pequenas e médias propriedades (OLIVEIRA \& HOLANDAFILHO, 2009).

O Estado de Rondônia ocupa o quinto lugar entre os maiores estados produtores de café do País e é o segundo maior produtor de café do tipo Conilon (Coffea canephora). Isso se deve a boa adaptação a regiões baixas, elevada produção, 
rusticidade e vigor, além de ser resistente ao nematóide das galhas, resistente à seca, devido ao exuberante sistema radicular e resistente ao agente da ferrugem (Hemileia vastatrix Berk.), que tem se mostrado bastante agressivo nas regiões produtoras de café, sendo considerado o principal problema fitossanitário da cultura (FERRÃO et al., 2004).

A broca-do-café (Hypothenemus hampei Ferrari) é considerada uma das pragas das regiões produtoras de café no mundo, atacando frutos em qualquer estágio de maturação, desde verdes até maduros e secos, podendo ocasionar perda total na produção (BARREIRA et al., 1990). Os altos índices de danos deste inseto em Rondônia se devem principalmente à umidade e temperatura altas (REIS et al., 2002). A diminuição na porcentagem de grãos perfeitos, o aumento de grãos quebrados, a perda de peso, a interferência no tipo do café, a queda de frutos brocados ainda no campo e a infestação por microorganismos são danos diretos ocasionados pela broca no processo de produção do café (REIS \& SOUZA, 1984).

O uso de inseticidas químicos para controle deste inseto tem sido de pouca eficiência entre os países cafeicultores da América do Sul, devido à seleção natural de linhagens de insetos resistentes, além de causar problemas ambientais, como a eliminação da fauna benéfica, a crescente contaminação do solo, água, atmosfera e seres vivos, além e danos acidentais ocasionados pela sua utilização. Estes fatos têm incentivado a pesquisa de métodos alternativos de controle da população de insetos (BUSTILLO, 2002).

Produtos de origem vegetal podem ser utilizados como fontes de recursos para a produção de inseticidas naturais, uma vez que são ricos em componentes bioativos, além do mais, podem desempenhar importante papel na interação da planta com o meio ambiente (RYAN, 1990). Em vista disso, a busca por novas substâncias a partir de fontes naturais, incluindo plantas, tem ganhado importância nas pesquisas científicas nos últimos anos (DUARTE, 2005).

Os óleos voláteis, ou essenciais, são misturas complexas de substâncias voláteis, lipofílicas, geralmente odoríferas e líquidas, de aparência oleosa à temperatura ambiente. Porém, a volatilidade, característica deste grupo de substâncias, o distingue dos óleos fixos. Outra característica importante é o aroma agradável e intenso da maioria dos óleos voláteis, razão de serem denominados como essências. Óleos essenciais podem ser obtidos de partes de plantas através de destilação por arraste a vapor d'água ou outros métodos de extração (SIMÕES \& SPITZER, 2004).

S. terebinthifolius é uma planta medicinal, popularmente conhecida como aroeira vermelha, utilizada para diversos fins, por exemplo, a casca do caule tem ação contra febre, hemoptises e afecções uterinas em geral. Da casca extrai-se um óleo empregado contra tumores e doenças da córnea (BORNHAUSEN, 2002). Além disso, o chá das folhas secas de $S$. terebinthifolius é utilizado contra febres, problemas do trato urinário, contra cistites, uretrites, blenorragia, problemas menstruais com excesso de sangramento e gripes (SOUZA \& LORENZI, 2008). O óleo essencial, rico em monoterpenos, é o principal responsável por várias atividades desta planta, especialmente como agente antimicrobiano contra vários tipos de bactérias e fungos, inclusive contra vírus de plantas, bem como atividade repelente contra a mosca doméstica (SILVA et al., 2011). O óleo essencial também é indicado em distúrbios respiratórios, possui ação regeneradora dos tecidos, queimaduras e problemas de pele (ALMEIDA, 1993).

Devido à necessidade de métodos seguros no controle de insetos na agricultura, este trabalho teve como objetivo avaliar a ação inseticida do óleo essencial de folhas de $S$. terebinthifolius sobre $H$. hampei.

\section{MATERIAL E MÉTODO}

As folhas $(1 \mathrm{~kg})$ de $S$. terebinthifolius utilizadas para a obtenção do óleo essencial foram coletadas em maio de 2007 na área experimental da Embrapa Rondônia, em Porto Velho-RO, trituradas e submetidas à hidrodestilação por duas horas, utilizando-se extratores de vidro tipo Clevenger modificado para obtenção do óleo essencial. O óleo foi analisado por cromatografia gasosa acoplada à espectrometria de massas (GC-EM) utilizando-se cromatógrafo HP 5890B Series II, acoplado a espectrômetro de massas HP-5971, equipado com coluna capilar de sílica fundida $\mathrm{J} \&$ W Scientific DB5 (30 m x 0,25 mm x 0,25 $\mu \mathrm{m})$. A análise cromatográfica (CG) foi obtida utilizando-se aparelho Hewlett Packard 5890 Series II equipado com detector de ionização de chama (FID) e coluna capilar de sílica fundida J \& W Scientific DB-5 (30 $\mathrm{m} \times 0,25 \mathrm{~mm} \times 0.25 \mu \mathrm{m}$ ); as temperaturas do injetor e detector foram, respectivamente, 220 e $285^{\circ} \mathrm{C}$. Usou-se o hélio como gás de arraste e uma vazão de $1 \mathrm{~mL} \mathrm{~min}^{-1}$; o programa de temperatura da coluna foi $40^{\circ} \mathrm{C}(1 \mathrm{~min})$ até $220^{\circ} \mathrm{C} \mathrm{a} 4^{\circ} \mathrm{C} \mathrm{min}{ }^{-1} ; 220$ até $280^{\circ} \mathrm{C}$

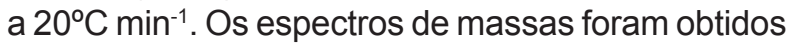
com impacto eletrônico de $70 \mathrm{eV}, 0,84 \mathrm{scan} / \mathrm{sec}$ de $\mathrm{m} / \mathrm{z} 40$ a 550. O hidrogênio foi usado como gás de arraste, com velocidade de fluxo $1,5 \mathrm{~mL} \mathrm{~min}^{-1}$, modo split (1:10). Os componentes foram identificados por comparação dos espectros de massas e índices de retenção (I.R.) com os da biblioteca do sistema e da

Rev. Bras. PI. Med., Campinas, v.15, n.4, supl.I, p.757-762, 2013. 
literatura (ADAMS, 1995). Os índices de retenção foram obtidos utilizando-se a série homóloga dos $n$-alcanos nas mesmas condições de operação.

Nos bioensaios, foram utilizados insetos adultos de $H$. hampei, oriundos da criação estoque da Embrapa Rondônia. Os insetos foram coletados em 350 frutos maduros de café, armazenados em caixas de madeira ( $26 \times 37 \times 13 \mathrm{~cm})$, com umidade de $45 \%$, acondicionadas em gaiolas com proteção de tela de filó, à temperatura de $25 \pm 2{ }^{\circ} \mathrm{C}$.

Com uma micropipeta, foram transferidos $250,0 \mu \mathrm{L}$ de óleo essencial para um balão volumétrico. O volume foi completado com acetona para $25,0 \mathrm{~mL}$, resultando na diluição de $10^{-2}$. Foi transferido $1,0 \mathrm{~mL}$ desta diluição para outro balão volumétrico, completando-se o volume com acetona para $25,0 \mathrm{~mL}$, obtendo-se assim a diluição de $10^{-3}$. Este procedimento foi repetido para obtenção das diluições de $10^{-4}$ a $10^{-8}$.

Após a evaporação da acetona, foram colocados os insetos adultos, avaliando-se sua mortalidade em duas épocas de avaliação, 24 e 48 horas após a aplicação do óleo essencial diluído. Para avaliação da ação tópica, os insetos foram mergulhados nas mesmas diluições por um minuto e, em seguida, colocados em placas de Petri com papel de filtro. Foram utilizados dez insetos por experimento, em quatro repetições, em delineamento inteiramente casualizado, em esquema fatorial. $\mathrm{Na}$ avaliação da mortalidade dos insetos foram considerados vivos todos os insetos que se moviam quando estimulados. Os dados referentes ao efeito do óleo essencial nos bioensaios foram submetidos à análise de regressão.

\section{RESULTADO E DISCUSSÃO}

A extração do óleo essencial das folhas de $S$. terebinthifolius forneceu rendimento de $0,8 \%$. Neste óleo foram identificados 37 constituintes químicos. Os componentes principais foram germacreno $D(25,0 \%)$, (E)- $\beta$-cariofileno (17,5\%) e $\delta$-elemeno (10,5\%). Os componentes identificados, índices de retenção e porcentagem relativa (\%) estão apresentados na Tabela 1.

Na Figura 1 estão apresentados os resultados do bioensaio em superfície contaminada, realizado com insetos de $H$. hampei, em relação a diferentes diluições do óleo essencial de folhas de $S$. terebinthifolius. Os resultados mostram que o óleo essencial de $S$. terebinthifolius foi eficiente na indução da mortalidade dos insetos e abre novas perspectivas quanto à sua utilização como inseticida natural no controle de pragas. Após 24 horas de bioensaio, observou-se mortalidade de 90,$0 ; 75,0$ e $72,5 \%$ nas diluições de $10^{-2}, 10^{-3}$ e $10^{-}$ ${ }^{4}$, enquanto nas demais diluições, $10^{-5}$ a $10^{-8}$, e no controle experimental, o efeito não atingiu $40 \%$ de mortalidade.

A mortalidade observada no controle experimental, $15,0 \%$, pode ser atribuída, em grande parte, à falta de alimento e à toxicidade residual da acetona, uma vez que a mesma possui em sua composição química piretróides. É importante

TABELA 1. Percentual dos componentes voláteis de folhas de $S$. terebinthifolius Raddi

\begin{tabular}{|c|c|c|c|c|c|}
\hline Composto & I.R. ${ }^{a}$ & $(\%)$ & Composto & I.R. ${ }^{a}$ & $(\%)$ \\
\hline$\alpha$-pineno & 940 & 1.2 & $\alpha$-cubebeno & 1345 & 1.7 \\
\hline 1-octen-3-ol & 974 & 2.0 & $\alpha$-copaeno & 1376 & 2.3 \\
\hline sabineno & 980 & 5.6 & $\beta$-bourboneno & 1383 & 0.8 \\
\hline$\beta$-pineno & 983 & 5.4 & $\beta$-cubebeno & 1390 & 3,0 \\
\hline 3-octanol & 993 & 0.2 & $\beta$-elemeno & 1392 & 5.3 \\
\hline$\beta$-myrceno & 995 & 0.1 & $(E)$ - $\beta$-cariofileno & 1422 & 17.5 \\
\hline$\delta$-3-careno & 1012 & $<0.1$ & aromadendreno & 1440 & $<0.1$ \\
\hline$\alpha$-terpineno & 1020 & $<0.1$ & alloaromadendreno & 1456 & $<0.1$ \\
\hline p-cymeno & 1024 & $<0.1$ & $\alpha$-humuleno & 1460 & 8.8 \\
\hline$\alpha$-felandreno & 1030 & 1.0 & $\gamma$-muuroleno & 1481 & 1.3 \\
\hline (Z)-ocimeno & 1038 & $<0.1$ & germacreno D & 1484 & 25.0 \\
\hline (E)-ocimeno & 1050 & $<0.1$ & $\beta$-selineno & 1487 & 1.0 \\
\hline$\gamma$-terpineno & 1064 & 0.4 & $\gamma$-calacoreno & 1540 & $<0.1$ \\
\hline$\alpha$-terpinoleno & 1098 & 0.5 & $\alpha$-cadineno & 1545 & $<0.1$ \\
\hline camfora & 1150 & $<0.1$ & óxido de epi-ligulyl* & 1561 & 6.0 \\
\hline borneol & 1167 & $<0.1$ & espatulenol & 1580 & 0.7 \\
\hline$\alpha$-terpineol & 1186 & 6.0 & óxido de carriofileno & 1588 & 0.5 \\
\hline acetato de bornila & 1284 & 0.3 & curzerenona & 1608 & $<0.1$ \\
\hline$\delta$-elemeno & 1340 & 10.3 & & & \\
\hline
\end{tabular}

aÍndice de retenção em DB-5. *Tentativa de identificação no espectro de massas (70 eV): 222(M+., 10), 207(100), 189(60), 164(25), 149(50), 137(75), 109(63), 95(44), 81(53), 69(30), 55(50), 41(46). 
ressaltar que a velocidade com que o óleo essencial provoca mortalidade pode ser de grande relevância, uma vez que, em condições de campo, o contato do inseto com o óleo pode ser relativamente rápido.

Após 48 horas, a mortalidade atingiu $100,0 \%$ apenas na diluição $10^{-2}$. Nas diluições $10^{-3}$ e $10^{-4}$ a mortalidade foi relativamente alta, 82,5 e $80,0 \%$, respectivamente. As diluições de e $10^{-5}$ a $10^{-8}$ resultaram em mortalidade igual ou inferior a $40 \%$. No controle experimental, observou-se $25,0 \%$ de mortalidade.

Na Figura 2 estão apresentados os resultados do bioensaio no qual se utilizou aplicação tópica do óleo essencial de $S$. terebinthifolius, sobre insetos de $H$. hampei, em diferentes diluições. Comparando-se as Tabelas 2 e 3, pode-se observar que, de forma geral, a aplicação tópica foi mais eficiente que a aplicação em superfície contaminada, apesar de não ter provocado 100,0\% de mortalidade.

É interessante observar que praticamente não houve variação entre os períodos de exposição (24 e 48 horas), indicando que a exposição tópica do inseto ao óleo provoca mortalidade rápida, com pouco ou nenhum efeito residual.

Todas as diluições foram eficientes em relação ao controle experimental, sendo que as diluições de $10^{-2}$ a $10^{-5}$ resultaram em 97,$5 ; 97,5$; 95,0 e $92,5 \%$ de mortalidade, respectivamente. As diluições de $10^{-6}$ a $10^{-8}$ resultaram em 82,$5 ; 85,0$ e $77,5 \%$, respectivamente, enquanto observou-se apenas $27,5 \%$ de mortalidade no controle.

Santos et al. (2007) avaliaram a atividade inseticida do óleo essencial de $S$. terebinthifolius sobre Acanthoscelides obtectus Say e Zabrotes subfasciatus Boheman em superfície contaminada, tendo sido observado $100 \%$ de mortalidade de A. obtectus em 24 horas de experimento para as diluições do óleo até $10^{-3}$, sendo que, no controle, a mortalidade atingiu $20 \%$. Com relação a $Z$. subfasciatus, apenas o óleo essencial puro e a diluição de $10^{-1}$ provocaram $100 \%$ de mortalidade, após 24 horas, enquanto no controle a mortalidade atingiu $25 \%$.

Santos et al., (2013) ao avaliar o potencial inseticida do extrato acetônico de raízes de Piper alatabaccum sobre $H$. hampei em aplicação tópica e superfície contaminada, verificaram que em ação tópica, os resultados foram eficientes na mortalidade dos insetos, observando-se em 48 horas de experimento que a mortalidade alcançou $80 \%$, na concentração de $0,5 \mathrm{mg} \cdot \mathrm{mL}^{-1}$. Enquanto que no controle a mortalidade atingiu $15 \%$.

Lima (2006) ao testar o extrato etanólico de sementes de Pachira aquatica Aubl., sobre $H$. hampei na concentração de $25 \mathrm{mg} \cdot \mathrm{mL}^{-1}$, verificouse que a mortalidade por exposição em superfície contaminada atingiu $100 \%$ contra $42 \%$ por aplicação tópica, no período de três horas.

Conforme Sallet (2006), ao avaliar os extratos etanólicos de Momordica charantia Hitebe e Piper tuberculatum Jacq., sobre $H$. hampei em superfície contaminada na concentração de 0,1 mg. $\mathrm{mL}^{-1}$, observou uma mortalidade de $100 \%$, diferindo significativamente das concentrações de 5 e $25 \mathrm{mg} \cdot \mathrm{mL}^{-1}$, que apresentaram mortalidade de $95 \mathrm{e}$ $80 \%$, respectivamente, nas duas primeiras horas do

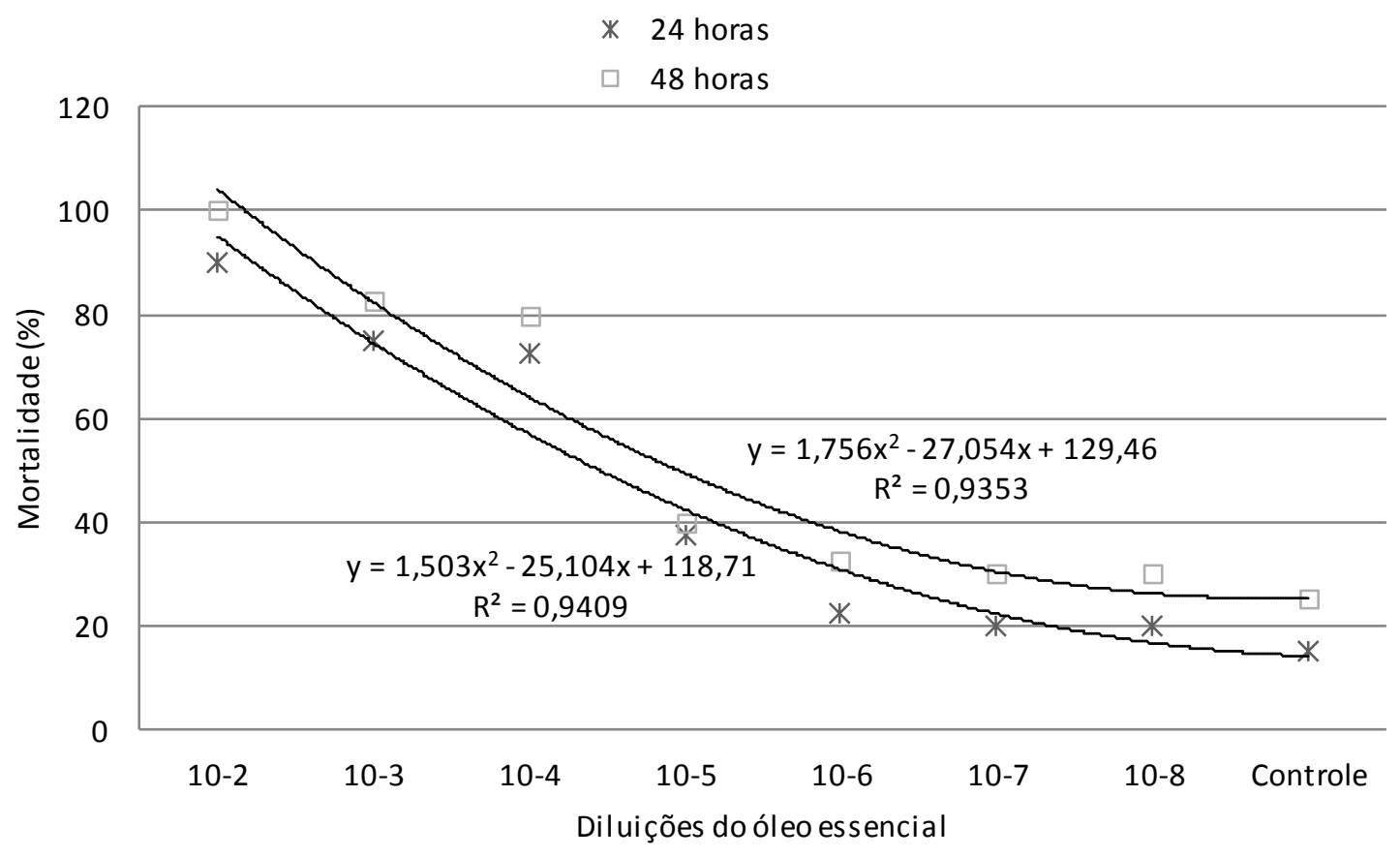

FIGURA 1. Efeito do óleo essencial de folhas de S. terebinthifolius sobre H. hampei, em superfície contaminada.

Rev. Bras. PI. Med., Campinas, v.15, n.4, supl.I, p.757-762, 2013. 


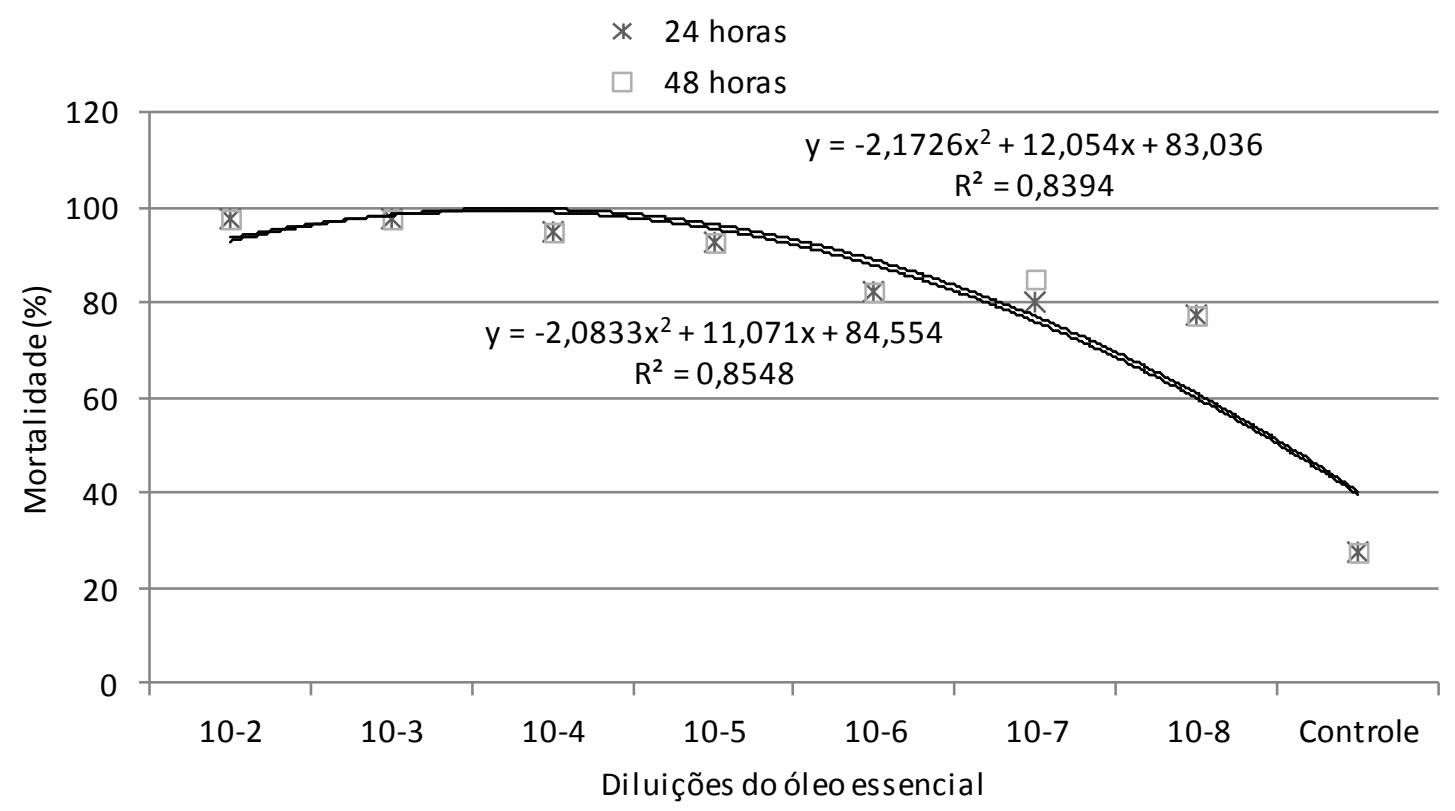

FIGURA 2. Efeito do óleo essencial de folhas de S. terebinthifolius sobre H. hampei, em aplicação tópica.

experimento, enquanto que no controle, não houve mortalidade dos insetos. Em comparação com as diluições testadas neste trabalho, verificou-se que $100 \%$ de mortalidade foi atingida com diluição dez vezes menor, de $10^{-2}$.

Santos et al., (2011) ao avaliar o potencial inseticida do extrato acetônico de raízes de Piper hispidum sobre $H$. hampei em aplicação tópica e superfície contaminada, verificaram que em superfície contaminada, os resultados foram eficientes na mortalidade dos insetos. Observouse em 48 horas de experimento que a mortalidade alcançou $95 \%$, na concentração de $0,5 \mathrm{mg} \cdot \mathrm{mL}^{-1}$, já a menor mortalidade dos insetos, foi observada na concentração de $0,2 \mathrm{mg} \cdot \mathrm{mL}^{-1}$ que atingiu somente $5 \%$ dos insetos. Enquanto que no controle a mortalidade atingiu $15 \%$.

Resultados de análises fitoquímicas registraram a presença de alto teor de tanino, biflavonóides e ácidos triterpênicos nas cascas de S. terebinthifolius e de até $5 \%$ de mono e sesquiterpenos nos óleos essenciais de frutos e folhas, sugerindo que alguns componentes dos óleos voláteis constituem uma proteção contra predadores e infestantes (MATOS, 2002).

Os óleos essenciais podem estar relacionados a diferentes funções na interação da planta com o ambiente, como defesa contra herbivoria e patógenos, competição entre plantas e atração de organismos benéficos, como polinizadores, dispersores de sementes e microrganismos simbiontes. Além disso, tais compostos também têm uma importante ação protetora em relação ao estresse abiótico, como aqueles associados a mudanças de temperatura, luminosidade, exposição à radiação ultravioleta, disponibilidade de nutrientes e distribuição geográfica (RAVEN et al., 2001). Os óleos essenciais não somente repelem insetos, mas também apresentam ação inseticida contra insetospraga específicos (ISMAN, 2000).

Trabalhos com óleos essenciais e extratos vegetais são frequentes no controle de pragas. Há vários estudos na literatura direcionados para a diminuição de produtos tóxicos que causam prejuízos ao meio ambiente. Neste trabalho, foi demonstrado o potencial inseticida do óleo essencial das folhas de $S$. terebinthifolius no controle de $H$. hampei, o que sugere seu potencial no controle deste inseto em condições de campo.

Pelo exposto, evidencia-se que o óleo essencial das folhas de $S$. terebinthifolius pode vir a ser usado como alternativa no controle de $H$. hampei. Com os resultados obtidos neste trabalho, pode-se concluir que o óleo essencial, além de ser um produto natural, apresenta potencial inseticida contra insetos de grãos armazenados, com a vantagem de minimizar o uso de produtos químicos preservando assim, o meio ambiente.

\section{AGRADECIMENTO}

Os autores agradecem ao Conselho Nacional de Desenvolvimento Científico e Tecnológico (CNPq) pela concessão de Bolsa de Iniciação Científica. 


\section{REFERÊNCIA}

ADAMS, R.P. Identification of Essential oil Components by Gas Chromatography/ Mass Spectrometry. 2.ed. Illinois: Allured Publishing Corporation, 1995. 469p.

ALMEIDA, E.R. Plantas medicinais brasileiras: conhecimentos populares e científicos. São Paulo: Hemus, 1993. 341p.

BARREIRA, J.P. et al. Introducción de espécies de porasitoides africanos a México para el control biologico de la broca del cafe, Hypothenemus hampei (Ferrari) (Coleoptera: Scolytidae). Folia Entomologica Mexicana, v.79, n.3, p.245-7, 1990.

BORNHAUSEN, R. Ervas do Sítio. Disponível em: <http:// www.ervasdositio.com.br/enciclopedia/enciclopedia. asp> Acesso em: 24 jan. 2002.

BUSTILLO, E.N. El manejo de cafetales y su relación con el control de la broca del cafe en Colombia. Colombia: Cenicafé, 2002. 40p.

COMPANHIA NACIONAL DE ABASTECIMENTO. Acompanhamento da Safra Brasileira, Café Safra 2011 primeira estimativa, janeiro/2011. Brasília: Conab, 2011. $25 p$.

DUARTE, M.C.T.; FIGUEIRA G.M.; SARTORATTO A.; REHDER V.L.G.; MACHADO, A.L.M.; DELARMELINA, C. Anti-Candida activity of essential oils and extracts from native and exotic medicinal plants used in Brazil. Journal of Etnopharmacology, v.97, n.2, p.305-311, 2005.

FERRÃO, R.G.; FONSECA, A.F.A.; FERRÃO, M.A.G.; MUNER, L.H.; VERDIN-FILHO, A.C.; VOLPI, P.S.; MARQUES, E.M.G.; ZUCATELI, F. Café Conilon: técnicas de produção com variedade melhoradas. Vitória: Incaper, 2004. 60p.

GUIMARÃES, R.J.; MENDES, A.N.G.; SOUZA, C.A. Estocagem e armazenagem: cafeicultura brasileira. Lavras: Universidade Federal de Lavras, 2002. 317p.

ISMAN, M.B. Plant essential oils for pest and disease management. Crop Protection, v.19, n.8, p.603-8, 2000.

LIMA, D.K.S. Atividade inseticida e fungicida do extrato etanólico de Pachira aquatica Aubl. sobre Hypothenemus hampei Ferrari e Fusarium spp. 2006. 62p. Dissertação (Mestrado em Biologia Experimental). Departamento de Botânica, Universidade Federal de Rondônia, Porto Velho.

MATOS, F.J.A. Farmácias vivas - sistema de utilização de plantas medicinais projetado para pequenas comunidades. Fortaleza: Universidade Federal do Ceará, 2002. 267p.

RAVEN, P.H.; EVERT, R.F.; CURTIS, H. Biologia vegetal. 6.ed. Rio de Janeiro: Guanabara, 2001. 960p.

OLIVEIRA, S.J.M.; HOLANDA-FILHO, Z.F. Aspectos econômicos, ambientais e sociais da produção cafeeira em diferentes sistemas em Rondônia. Porto Velho: Embrapa Rondônia, 2009, 6p. (Embrapa Rondônia. Comunicado Técnico, 351).

REIS, P.R.; SOUZA, J.C. Pragas do cafeeiro. Informe agropecuário, v.109, n.10, p.41-7, 1984.

REIS, P.R.; SOUZA, J.C.; VENZON, M. Manejo ecológico das principais pragas do cafeeiro. Informe Agropecuário, v.214, n.23, p.83-99, 2002.

RYAN, C.A. Proteinase inhibitors in plants: Genes for improving defenses against insects and pathogens. Annual Review of Phytopathology, v.28, n.1, p.42549, 1990.

SALLET, L.A.P. Bioatividade dos extratos etanólicos de Momordica charantia H. e Piper tuberculatum J. sobre Hypothenemus hampei F. e Beauveria bassiana B. 2006. 78p. Dissertação (Mestrado em Biologia Experimental). Departamento de Botânica, Universidade Federal de Rondônia, Porto Velho.

SANTOS, M.R.A. et al. Atividade inseticida do óleo essencial de Schinus terebinthifolius Raddi sobre Acanthoscelides obtectus Say e Zabrotes subfasciatus. Revista Fitos, v.3, n.1, p.77-84, 2007.

SANTOS, M.R.A. et al. Atividade inseticida do extrato de raiz de Piper hispidum H.B.K. (Piperaceae) sobre Hypothenemus hampei Ferrari. Revista Saúde e Pesquisa, v.4, n.3, p.335-340, 2011.

SANTOS, M.R.A. et al. Composição química e atividade inseticida do extrato acetônico de Piper alatabaccum Trel \& Yuncker (Piperaceae) sobre Hypothenemus hampei Ferrari. Revista Brasileira de Plantas Medicinais, v.15, n.3, p.332-336, 2013.

SILVA, N.L.A.; MIRANDA, F.A.A.; CONCEIÇÃO, G.M. Triagem fitoquímica de plantas do Cerrado, da área de proteção ambiental municipal do Inhamum, Caxias, Maranhão. Scientia Plena, v.6, n.2, p.1-17, 2010.

SILVA, M.A. et al. Óleo essencial de aroeira vermelha como aditivo na ração de frangos de corte. Ciência Rural, v.41, n.4, p.676-681, 2011.

SIMÕES, C.M.O.; SPITZER, V. Óleos Voláteis. In: SIMÕES, C.M.O et al. Farmacognosia da planta ao medicamento, 5. ed. Porto Alegre/Florianópolis: Editora da UFRGS/Editora da UFSC, p. 468-495, 2004.

SOUZA, V.C.; LORENZI, H. Botânica sistemática: guia ilustrado para identificação das famílias de Fanerógamas nativas e exóticas no Brasil, baseado em APG II. 2ed. Nova Odessa: Instituto Plantarum, 2008. 704p. 